\title{
Low oxygen saturation and mortality in an adult cohort: the Troms $\varnothing$ study
}

\author{
Monica Linea Vold ${ }^{1,2^{*}}$, Ulf Aaseb ${ }^{1,3 \dagger}$, Tom Wilsgaard $^{2 \dagger}$ and Hasse Melbye ${ }^{2 \dagger}$
}

\begin{abstract}
Background: Oxygen saturation has been shown in risk score models to predict mortality in emergency medicine. The aim of this study was to determine whether low oxygen saturation measured by a single-point measurement by pulse oximetry $\left(\mathrm{SpO}_{2}\right)$ is associated with increased mortality in the general adult population.

Methods: Pulse oximetry was performed in 5,152 participants in a cross-sectional survey in Tromsø, Norway, in 2001-2002 ("Tromsø 5"). Ten-year follow-up data for all-cause mortality and cause of death were obtained from the National Population and the Cause of Death Registries, respectively. Cause of death was grouped into four categories: cardiovascular disease, cancer except lung cancer, pulmonary disease, and others. $\mathrm{SpO}_{2}$ categories were assessed as predictors for all-cause mortality and death using Cox proportional-hazards regression models after correcting for age, sex, smoking history, body mass index (BMI), C-reactive protein level, self-reported diseases, respiratory symptoms, and spirometry results.
\end{abstract}

Results: The mean age was 65.8 years, and 56\% were women. During the follow-up, 1,046 (20.3\%) participants died. The age- and sex-adjusted hazard ratios (HRs) (95\% confidence intervals) for all-cause mortality were 1.99 (1.33-2.96) for $\mathrm{SpO}_{2} \leq 92 \%$ and 1.36 (1.15-1.60) for $\mathrm{SpO}_{2}$ 93-95\%, compared with $\mathrm{SpO}_{2} \geq 96 \%$. In the multivariable Cox proportional-hazards regression models that included self-reported diseases, respiratory symptoms, smoking history, BMI, and CRP levels as the explanatory variables, $\mathrm{SpO}_{2}$ remained a significant predictor of all-cause mortality. However, after including forced expiratory volume in $1 \mathrm{~s}$ percent predicted ( $\mathrm{FEV}_{1} \%$ predicted), this association was no longer significant. Mortality caused by pulmonary diseases was significantly associated with $\mathrm{SpO}_{2}$ even when $\mathrm{FEV}_{1} \%$ predicted was included in the model.

Conclusions: Low oxygen saturation was independently associated with increased all-cause mortality and mortality caused by pulmonary diseases. When $\mathrm{FEV}_{1} \%$ predicted was included in the analysis, the strength of the association weakened but was still statistically significant for mortality caused by pulmonary diseases.

\section{Background}

Pulse oximeters are cheap and are used widely as noninvasive devices for estimating oxygen saturation $\left(\mathrm{SpO}_{2}\right)$. Pulse oximetry is used extensively in clinical medicine to evaluate and monitor patients. Low oxygen saturation or hypoxemia is associated with conditions or diseases involving ventilation-perfusion mismatch in the lungs, hypoventilation, right-to-left shunts, reduced diffusion capacity, and reduced oxygen partial pressure in inspired

\footnotetext{
* Correspondence: monica.linea.vold@unn.no

${ }^{\dagger}$ Equal contributors

'Department of Respiratory Medicine, University Hospital of North Norway, 9038 Tromsø, Norway

${ }^{2}$ Department of Community Medicine, University of Troms $\varnothing$, Troms $\varnothing$, Norway Full list of author information is available at the end of the article
}

air. There is no clear cut-off point for abnormal oxygen saturation, but $\mathrm{SpO}_{2} \leq 95 \%$ is used in most adult studies. In materials for blood gas reference values, Crapo et al. reported a mean arterial oxygen saturation $\left(\mathrm{SaO}_{2}\right)$ of 95.5-96.9\% (standard deviation (SD) 0.4-1.4) [1]. In a more recent paper, the median $\mathrm{SaO}_{2}$ was $98.2 \%$ (range 96.6-99.5\%) in the 20-39-year-old age group and 98.0\% (range 95.1-99.7\%) in the 40-76-year-old age group [2]. $\mathrm{SaO}_{2}$ decreased marginally with age by about $0.20 \%$ per decade. A resting $\mathrm{SpO}_{2} \leq 95 \%$ has been found to predict oxygen desaturation during sleep, exercise, and air plane travel in chronic obstructive pulmonary disease (COPD) patients [3-5]. $\mathrm{SpO}_{2} \leq 95 \%$ has also been identified as a risk factor for postoperative pulmonary complications [6]. The value of $96 \%$ seems a reasonable cut-off value. 
An $\mathrm{SpO}_{2}$ cut-off value of $\leq 92 \%$ is used when screening for respiratory failure in COPD patients [7]. In emergency medicine, low $\mathrm{SpO}_{2}$ has been shown to be associated with increased mortality $[8,9]$ and is included together with other vital signs when calculating the risk score for predicting prognosis [10-13]. Different risk-scoring models to predict mortality use different limits from $<90$ to $\leq 95 \%$ [10-14]. In lung diseases such as COPD, the partial pressure of oxygen $\left(\mathrm{PaO}_{2}\right)$ is used most often in models to predict mortality [15]. Higher oxygen saturation has been shown in survivors [16,17], but neither $\mathrm{SpO}_{2}$ nor $\mathrm{PaO}_{2}$ was found to be a significant predictor when added to a validated multi-dimensional disease rating that included the body mass index (B), degree of airflow obstruction $(\mathrm{O})$, dyspnoea (D), and exercise capacity (E) (BODE Index) in multivariable analysis [15].

There is limited information about low oxygen saturation and its association with mortality in the general population. In a previous study, we found that the most important predictors for low oxygen saturation in an adult population were increased body mass index (BMI) and reduced lung function, which was defined as decreased forced expiratory volume in $1 \mathrm{~s}$ percent predicted $\left(\mathrm{FEV}_{1} \%\right.$ predicted) [18]. We also found that smoking history, dyspnoea, elevated haemoglobin concentration, age, and male sex predicted low oxygen saturation. $\mathrm{FEV}_{1} \%$ predicted is a predictor of mortality in both surveys of the general population [19] and COPD studies [15]. Low BMI has been associated with increased mortality both in epidemiological surveys $[20,21]$ and COPD studies [22,23].

It is known that older age, male sex, smoking history (both current and former smoker), pack years (former smoker is often not significant when pack years are included) [19], and a history of cardiovascular disease (CVD), hypertension, or diabetes predict mortality in studies of the general adult population [24]. Biomarkers such as increased C-reactive protein (CRP) concentration have been found to predict mortality in both the general population [25] and patients with COPD [26].

The aim of this study was to examine whether a singlepoint measurement of a low $\mathrm{SpO}_{2}$ is associated with allcause mortality and cause of death, especially death due to pulmonary diseases, in the general adult population after correcting for other established risk factors.

\section{Methods}

\section{Subjects}

The Tromsø Study comprises repeated cross-sectional population-based surveys, which were initiated in 1974 [27]. Tromsø is a university city in northern Norway where the population recently exceeded 70,000. Troms $\varnothing$ is situated at sea-level, and the oxygen partial pressure in inspired air is not reduced. The fifth Tromsø Study survey was performed in 2001-2002 and was conducted by the Department of Community Medicine, University of Troms $\varnothing$, in co-operation with the National Health Screening Service. In the fourth survey, all inhabitants aged $55-74$ years and $5-10 \%$ of the samples in the other age groups between 25 and 84 years were asked to take part in a second, more-extensive medical examination (77\% agreed to participate). All participants from this second visit were invited to participate in the Tromsø 5 survey and were eligible for a second visit. In Tromsø 5, the first visit was attended by 8,130 subjects, which was $79 \%$ of those invited. At the second visit, 5,905 attended (84\%), and $\mathrm{SpO}_{2}$ was measured by pulse oximetry in 5,152 participants (Figure 1). Lack of staff was the main reason why pulse oximetry and spirometry were not performed in $13 \%$ of the participants.

\section{Examinations}

A questionnaire was mailed together with an invitation to participate in the study. The questionnaire included questions about the participant's history of diseases, respiratory symptoms, and smoking habits. Participants who reported experiencing angina pectoris, myocardial infarction, or cerebral stroke were classified as having "self-reported CVD". Participants who used antihypertensive drugs were classified as having "self-reported hypertension". The examinations at the first visit included height and weight, and BMI $\left(\mathrm{kg} / \mathrm{m}^{2}\right)$ was calculated.

Pulse oximetry and spirometry were measured during the second visit. $\mathrm{SpO}_{2}$ values were measured with a digital handheld pulse oximeter (Onyx II, model 9550, Nonin Medical, Inc., Plymouth, MN, USA). The participants rested at least 15 minutes before the measurement. The highest of three measurements was recorded. The manufacturer's testing has shown that only values between $70 \%$ and $100 \%$ are accurate to within \pm 2 digits, and values $<70 \%$ were regarded as invalid.

Spirometry was performed using the Vmax Legacy 20 system (VIASYS Healthcare Respiratory Technologies, Yorba Linda, CA, USA). American Thoracic Society criteria [28] were followed. Norwegian reference values for pre-bronchodilatory spirometry [29] were used because reversibility testing was not performed. Calibration of the instrument was performed every morning and as the machine required. Three trained technicians conducted the spirometry. Current drug therapy was not interrupted before the test. Both pulse oximetry and spirometry were recorded in 5,131 individuals, and a valid $\mathrm{FEV}_{1} \%$ predicted was obtained in 4,988 of these participants.

On the same day, as part of the second examination, blood was drawn for measurement of the concentrations of haemoglobin [30] and CRP. CRP concentration was measured using a high-sensitivity immunoturbidimetric assay [31]. 


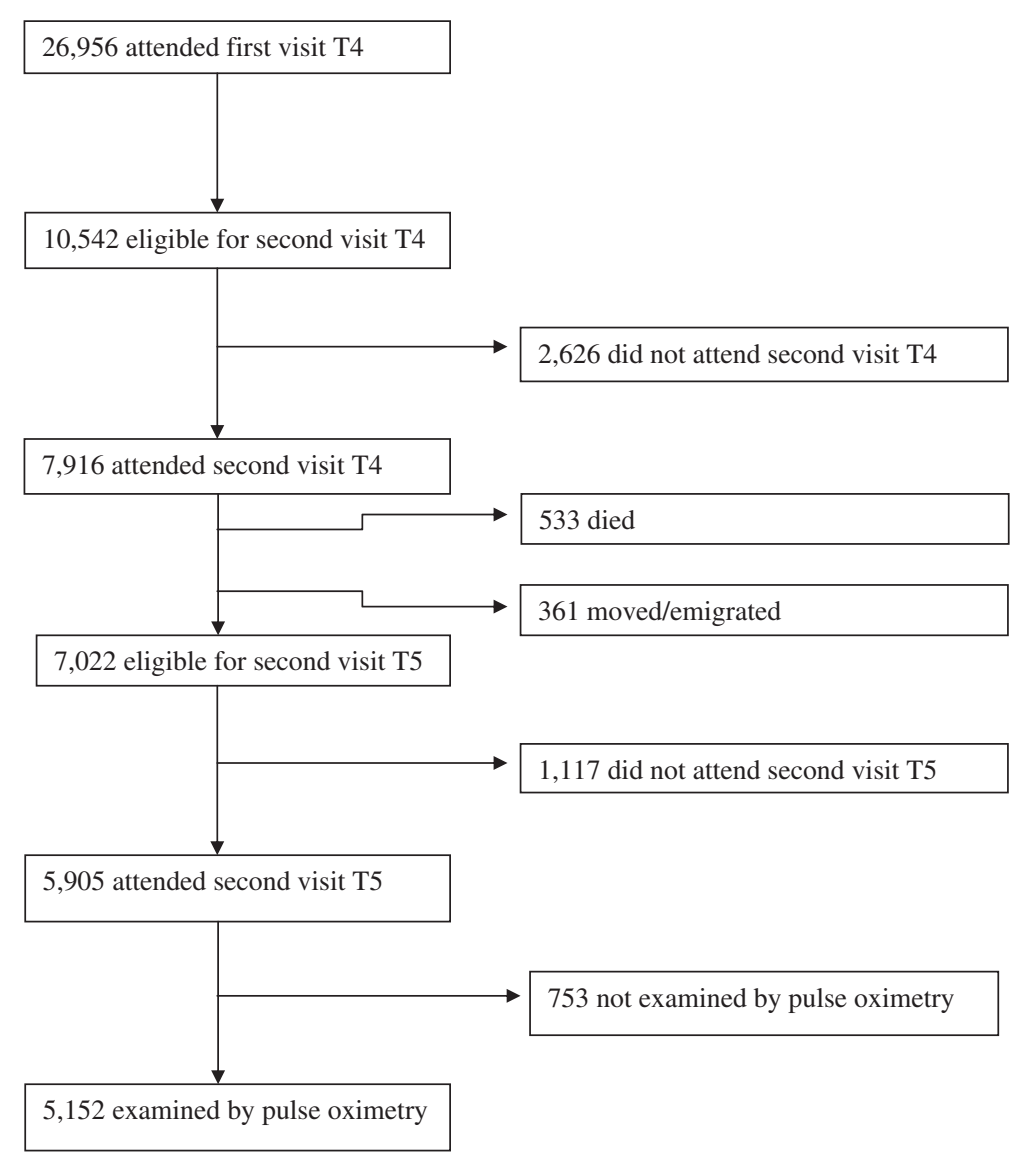

Figure 1 Flow chart of participants from Tromsø 4 (T4) to Tromsø 5 (T5).

\section{Statistical analysis}

Ten-year follow-up data for all-cause mortality were obtained from the National Population Register of Norway and causes of death from the National Cause of Death Registry. Subjects who emigrated were censored at the date of emigration. If subjects had not died or emigrated, they were censored at 10 years from the baseline. The causes of death were classified into four categories: CVD, cancer except lung cancer, pulmonary disease (including COPD, asthma, interstitial lung diseases, sequelae of tuberculosis, and lung cancer), and others. Continuous variables were categorized. We defined a low pulse oximetry value as an $\mathrm{SpO}_{2} \leq 95 \% . \mathrm{SpO}_{2}$ values were categorized into three groups: reduced, $\leq 92 \%$; mildly reduced, $93-95 \%$; and normal, $\geq 96 \%$. Characteristics of the participants were categorized according to $\mathrm{SpO}_{2}$ and mortality status, and differences were assessed using the chi-square test.

Associations with all-cause mortality and mortality caused by pulmonary diseases were analysed by Cox proportionalhazards regression for $\mathrm{SpO}_{2}$, smoking history, self-reported respiratory symptoms and diseases, BMI, CRP concentration, and spirometry measures, and were adjusted for age and sex. The significant predictors of mortality at the 5\% level were entered into multivariable Cox proportionalhazards regression models. Knowing that $\mathrm{FEV}_{1} \%$ predicted is associated with both $\mathrm{SpO}_{2}$ and mortality, models with and without $\mathrm{FEV}_{1} \%$ predicted included were applied. IBM SPSS statistical software version 20 (IBM, Armonk, NY, USA) was used.

The Regional Committee for Medical and Health Research Ethics in North Norway approved the Tromsø 5 survey. All participants gave written informed consent.

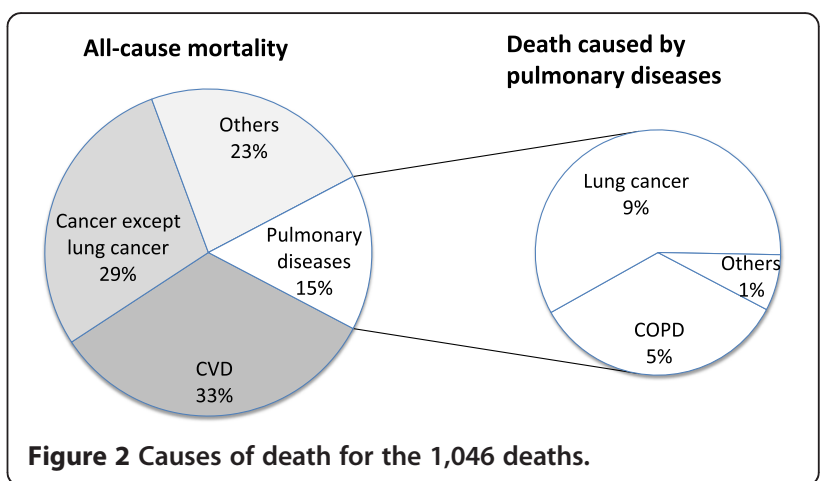


Table 1 Baseline characteristics classified by arterial oxygen saturation $\left(\mathrm{SpO}_{2}\right)$ in 5,152 participants

\begin{tabular}{|c|c|c|c|c|c|c|c|}
\hline & \multicolumn{2}{|c|}{$\leq 92 \%$} & \multicolumn{2}{|c|}{$93-95 \%$} & \multicolumn{2}{|l|}{$\geq 96 \%$} & \multirow[t]{2}{*}{ p-value } \\
\hline & $\bar{n}$ & $(\%)$ & $\mathrm{n}$ & (\%) & $\bar{n}$ & (\%) & \\
\hline All & & 53 & (1.0) & 537 & $(10.4)$ & 4,562 & $(88.5)$ \\
\hline Sex & & & & & & & 0.47 \\
\hline Female & 34 & $(1.2)$ & 297 & $(10.3)$ & 2,556 & $(88.5)$ & \\
\hline Male & 19 & $(0.8)$ & 240 & $(10.6)$ & 2,006 & (88.6) & \\
\hline Age (years) & & & & & & & $<0.001^{*}$ \\
\hline$<60$ & 1 & $(0.1)$ & 57 & (5.3) & 1,027 & $(94.7)$ & \\
\hline $60-70$ & 16 & $(0.7)$ & 217 & $(10.2)$ & 1,902 & (89.1) & \\
\hline$\geq 70$ & 36 & (1.9) & 263 & $(13.6)$ & 1,633 & $(84.5)$ & \\
\hline \multicolumn{8}{|l|}{ Self-reported diseases } \\
\hline CVD & & & & & & & $<0.001$ \\
\hline No & 39 & $(0.9)$ & 410 & (9.6) & 3,814 & (89.5) & \\
\hline Yes & 14 & (1.6) & 127 & $(14.3)$ & 748 & $(84.1)$ & \\
\hline Asthma & & & & & & & $<0.001$ \\
\hline No & 37 & $(0.8)$ & 448 & (9.6) & 4,197 & (89.6) & \\
\hline Yes & 16 & (3.4) & 89 & $(18.9)$ & 365 & $(77.7)$ & \\
\hline COPD & & & & & & & $<0.001$ \\
\hline No & 39 & $(0.8)$ & 476 & (9.8) & 4,366 & (89.4) & \\
\hline Yes & 14 & $(5.2)$ & 61 & $(22.5)$ & 196 & $(72.3)$ & \\
\hline Diabetes & & & & & & & 0.004 \\
\hline No & 49 & $(1.0)$ & 499 & $(10.1)$ & 4,373 & (88.9) & \\
\hline Yes & 4 & $(1.7)$ & 38 & $(16.5)$ & 189 & $(81.8)$ & \\
\hline Hypertension & & & & & & & 0.020 \\
\hline No & 40 & $(1.0)$ & 378 & $(9.7)$ & 3,463 & $(89.2)$ & \\
\hline Yes & 13 & $(1.0)$ & 159 & $(12.5)$ & 1099 & (86.5) & \\
\hline Smoking history & & & & & & & $0.001^{*}$ \\
\hline Never & 16 & $(0.9)$ & 141 & $(8.1)$ & 1,581 & (91.0) & \\
\hline Former & 21 & $(1.0)$ & 241 & $(11.6)$ & 1,819 & (87.4) & \\
\hline Current & 16 & $(1.2)$ & 155 & $(11.6)$ & 1,162 & $(87.2)$ & \\
\hline \multicolumn{8}{|l|}{ Self-reported symptoms } \\
\hline Dyspnoea $^{\#}$ & & & & & & & $<0.001^{*}$ \\
\hline 0 & 17 & $(0.6)$ & 221 & $(8.0)$ & 2,511 & (91.3) & \\
\hline 1 & 17 & $(0.8)$ & 244 & $(11.9)$ & 1,785 & $(87.2)$ & \\
\hline$\geq 2$ & 19 & (5.3) & 72 & $(20.2)$ & 266 & $(74.5)$ & \\
\hline Chronic cough with sputum & & & & & & & $<0.001$ \\
\hline No & 44 & $(0.9)$ & 460 & $(9.7)$ & 4,261 & (89.4) & \\
\hline Yes & 9 & $(2.3)$ & 77 & $(19.9)$ & 301 & $(77.8)$ & \\
\hline BMI $\left(\mathrm{kg} / \mathrm{m}^{2}\right)$ & & & & & & & $<0.001^{*}$ \\
\hline$<18.5$ & 1 & $(2.0)$ & 6 & $(12.2)$ & 42 & $(85.7)$ & \\
\hline $18.5-24.9$ & 16 & $(1.0)$ & 107 & $(6.4)$ & 1,548 & (92.6) & \\
\hline $25.0-29.9$ & 21 & $(0.9)$ & 239 & $(10.2)$ & 2,082 & $(88.9)$ & \\
\hline$\geq 30.0$ & 15 & (1.4) & 180 & $(17.0)$ & 865 & (81.6) & \\
\hline
\end{tabular}


Table 1 Baseline characteristics classified by arterial oxygen saturation $\left(\mathrm{SpO}_{2}\right)$ in $\mathbf{5 , 1 5 2}$ participants (Continued)

\begin{tabular}{|c|c|c|c|c|c|c|c|}
\hline CRP (mg/L) & & & & & & & $<0.001$ \\
\hline$<5$ & 36 & $(0.8)$ & 421 & $(9.7)$ & 3,871 & $(89.4)$ & \\
\hline$\geq 5$ & 17 & $(2.3)$ & 109 & $(14.7)$ & 615 & $(83.0)$ & \\
\hline Haemoglobin ${ }^{\S}$ & & & & & & & 0.29 \\
\hline supper limit & 48 & $(1.0)$ & 469 & $(10.3)$ & 4,052 & $(88.7)$ & \\
\hline > upper limit & 0 & $(0.0)$ & 4 & $(21.1)$ & 15 & $(78.9)$ & \\
\hline $\mathrm{FEV}_{1} \%$ predicted & & & & & & & $<0.001^{*}$ \\
\hline$<50$ & 16 & $(8.2)$ & 66 & $(34.0)$ & 112 & $(57.7)$ & \\
\hline $50-80$ & 22 & (1.3) & 223 & (13.3) & 1,427 & $(85.3)$ & \\
\hline$\geq 80$ & 13 & $(0.4)$ & 227 & $(7.3)$ & 2,882 & $(92.3)$ & \\
\hline $\mathrm{FEV}_{1} / \mathrm{FVC} \%$ & & & & & & & $<0.001$ \\
\hline$<0.7$ & 26 & $(2.4)$ & 185 & $(16.8)$ & 890 & $(80.8)$ & \\
\hline$\geq 0.7$ & 25 & $(0.6)$ & 335 & $(8.6)$ & 3,551 & $(90.8)$ & \\
\hline
\end{tabular}

"Chi-square trend.

\#Dyspnoea: 0, no dyspnoea; 1, dyspnoea walking rapidly on level ground or up a moderate slope; $\geq 2$, dyspnoea walking slowly on level ground, washing or dressing, or at rest.

ङUpper limits: women, $16.0 \mathrm{~g} / \mathrm{dL} ;$ men, $17.0 \mathrm{~g} / \mathrm{dL}$.

Definitions of abbreviations: $\mathrm{SpO}_{2}$, arterial oxygen saturation as measured by pulse oximetry; CVD, cardiovascular disease; COPD, chronic obstructive pulmonary disease; BMI, body mass index; CRP, C-reactive protein; FEV 1 , forced expiratory volume in $1 \mathrm{~s}$; FVC, forced vital capacity.

\section{Results}

$\mathrm{SpO}_{2}$ values were recorded for 5,152 people in Tromsø 5. Their mean age was 65.8 years (SD 9.5; range 32-89 years), and 2,887 (56\%) were women. During the follow-up period from 2001-2002 until 2011-2012, 1,046 (20.3\%) died: 346 (33.1\%) died of CVD, 299 (28.6\%) of cancer except lung cancer, 161 (15.4\%) of pulmonary disease, and 240 (22.9\%) of other diseases (Figure 2). The mean follow-up period was 9.2 years (SD 2.0). An $\mathrm{SpO}_{2} \leq 95 \%$ was found in $11.5 \%$ of the population.

Table 1 shows the baseline characteristics grouped according to $\mathrm{SpO}_{2}$. Low $\mathrm{SpO}_{2}$ was significantly associated with older age, self-reported diseases and symptoms, smoking history, high BMI and CRP concentration, and low $\mathrm{FEV}_{1} \%$ predicted and $\mathrm{FEV}_{1}$ / forced vital capacity (FVC)\%. A high haemoglobin concentration was not significantly associated with low $\mathrm{SpO}_{2}$ and was not included in further analysis.

Table 2 shows the characteristics according to mortality status. The group of participants who had died were more likely to have been older and male; to have smoked more; and to have had more self-reported diseases and respiratory symptoms, a lower $\mathrm{BMI}, \mathrm{FEV}_{1} \%$ predicted, $\mathrm{FEV}_{1} / \mathrm{FVC} \%$, and $\mathrm{SpO}_{2}$, and a higher CRP concentration. The frequency of death due to pulmonary diseases increased by decreasing $\mathrm{SpO}_{2}$ : 104 out of 4563 (2.3\%) participants with baseline $\mathrm{SpO}_{2}>96 \%$, 45 out of 537 (8.4\%) with $\mathrm{SpO}_{2}$ 93-95\%, and 12 out of $53(22.6 \%)$ with $\mathrm{SpO}_{2} \leq$ $92 \%, \mathrm{p}<0.001$.

Figure 3 shows the Kaplan-Meier survival curve for the different levels of $\mathrm{SpO}_{2}$. After adjusting for age and sex in the Cox proportional-hazards regression, the following factors were significantly associated with allcause mortality and mortality caused by pulmonary diseases: lower $\mathrm{SpO}_{2}, \mathrm{FEV}_{1} \%$ predicted, $\mathrm{FEV}_{1} / \mathrm{FVC} \%$, and BMI; higher CRP concentration; smoking history; and self-reported diseases and respiratory symptoms (Table 3). The highest HRs for all-cause mortality were found for $\mathrm{FEV}_{1} \%$ predicted $<50$, current smoking, history of diabetes, and $\mathrm{SpO}_{2} \leq 92 \%$ (3.07, 2.11, 2.08, and 1.99, respectively). For pulmonary diseases, the highest HRs were found for $\mathrm{FEV}_{1} \%$ predicted <50, current smoking, and $\mathrm{SpO}_{2} \leq 92 \%(16.35,14.21$, and 9.12, respectively) (Table 4).

A multivariable Cox proportional-hazards regression model for all-cause mortality that included all the variables except spirometry values produced HRs of 1.73 (95\% confidence interval (CI) 1.15-2.60) and 1.27 (95\% CI 1.06-1.51) for an $\mathrm{SpO}_{2} \leq 92 \%$ and 93-95\%, respectively. However, adding $\mathrm{FEV}_{1} \%$ predicted as an explanatory variable in the model decreased the $\mathrm{HRs}$ of $\mathrm{SpO}_{2}$ significantly, and although the association indicated a trend, it was not significant (Table 3).

Using the same models with mortality caused by pulmonary diseases as the outcome (Table 4), $\mathrm{SpO}_{2}$ was a significant variable, even when $\mathrm{FEV}_{1} \%$ predicted was included. The HRs for $\mathrm{SpO}_{2} \leq 92 \%$ and $93-95 \%$ were 3.17 (95\% CI 1.53-6.56) and 1.97 (95\% CI 1.33-2.92), respectively. Examining the $\mathrm{HR}$ of low $\mathrm{SpO}_{2}$ for any other cause of death showed no significant associations except for heart failure (20 deaths), which occurred in a subgroup of those who had died from CVD. The HRs for death caused by heart failure was also significantly increased when $\mathrm{FEV}_{1} \%$ predicted was included in the model. $\mathrm{FEV}_{1} \%$ predicted was significantly associated with mortality 
Table 2 Baseline characteristics classified by 10-year mortality status in 5,152 participants

\begin{tabular}{|c|c|c|c|c|}
\hline & Total (n) & Dead (n) & $\%$ & $p$-value \\
\hline All & 5,152 & 1,046 & (20.3) & \\
\hline Sex & & & & $<0.001$ \\
\hline Female & 2,887 & 459 & (15.9) & \\
\hline Male & 2,265 & 587 & $(25.9)$ & \\
\hline Age (years) & & & & $<0.001^{*}$ \\
\hline$<60$ & 1,085 & 43 & $(4.0)$ & \\
\hline $60-70$ & 2,135 & 274 & (12.8) & \\
\hline$\geq 70$ & 1,932 & 729 & (37.7) & \\
\hline
\end{tabular}

Self-reported diseases

CVD

$\begin{array}{rll}\text { No } & 4,263 & 742 \\ \text { Yes } & 889 & 304 \\ \text { Asthma } & & \\ \text { No } & 4,682 & 914 \\ \text { Yes } & 470 & 132 \\ \text { COPD } & & \\ \text { No } & 4,881 & 950 \\ \text { Yes } & 271 & 96\end{array}$

Diabetes

$\begin{array}{lll}\text { No } & 4,921 & 959 \\ \text { Yes } & 231 & 87\end{array}$

Hypertension

No $\quad 3,881$

Yes

1271

Smoking history

$\begin{array}{lll}\text { Never } & 1,736 & 269 \\ \text { Former } & 2,083 & 464 \\ \text { Current } & 1,333 & 313\end{array}$

Self-reported symptoms

Dyspnoea $^{\#}$

$\begin{array}{lll}0 & 2,749 & 486 \\ 1 & 2,046 & 437 \\ \geq 2 & 357 & 123\end{array}$

Chronic cough with sputum

$\begin{array}{lll}\text { No } & 4,765 & 920 \\ \text { Yes } & 387 & 126\end{array}$

BMI $\left(\mathrm{kg} / \mathrm{m}^{2}\right)$

$<18.5$

18.5-24.9 1,671

25.0-29.9 2,342

$\geq 30.0$

1,060

742

304

50

96

7

$<0.001^{*}$

$$
<0.001
$$$$
<0.001
$$

$<0.001$

$<0.001$

$$
<0.001
$$

$$
<0.001
$$

$<0.001$

(23.5)

$\begin{array}{lll} & & <0.001^{*} \\ 86 & (17.7) & \\ 37 & (21.4) \\ 23 & (34.5)\end{array}$

20

\begin{tabular}{|c|c|c|c|c|}
\hline CRP (mg/L) & & & & $<0.001$ \\
\hline$<5$ & 4,328 & 808 & (18.7) & \\
\hline$\geq 5$ & 741 & 213 & (28.7) & \\
\hline $\mathrm{FEV}_{1} \%$ predi & & & & $<0.001^{*}$ \\
\hline$<50$ & 194 & 99 & (51.0) & \\
\hline $50-80$ & 1,672 & 434 & (26.0) & \\
\hline$\geq 80$ & 3,122 & 456 & (14.6) & \\
\hline $\mathrm{FEV}_{1} / \mathrm{FVC} \%$ & & & & $<0.001$ \\
\hline$<70$ & 1,101 & 386 & (35.1) & \\
\hline$\geq 70$ & 3,911 & 612 & (15.6) & \\
\hline $\mathrm{SpO}_{2}(\%)$ & & & & $<0.001^{*}$ \\
\hline$\leq 92$ & 53 & 25 & $(47.2)$ & \\
\hline 93-95 & 537 & 163 & (30.4) & \\
\hline$\geq 96$ & 4,562 & 858 & (18.8) & \\
\hline
\end{tabular}

Table 2 Baseline characteristics classified by 10-year mortality status in 5,152 participants (Continued)

"Chi-square trend.

"Dyspnoea: 0, no dyspnoea; 1, dyspnoea walking rapidly on level ground or up a moderate slope; $\geq 2$, dyspnoea walking slowly on level ground, washing or dressing, or at rest.

Definitions of abbreviations: CVD, cardiovascular disease; COPD, chronic obstructive pulmonary disease; BMI, body mass index; CRP, C-reactive protein; $\mathrm{FEV}_{1}$, forced expiratory volume in $1 \mathrm{~s}$; FVC, forced vital capacity; $\mathrm{SpO}_{2}$, arterial oxygen saturation as measured by pulse oximetry.

caused by CVD, cancer except lung cancer, and pulmonary diseases but not with other diseases.

$\mathrm{FEV}_{1} / \mathrm{FVC} \%$ was not significantly associated with allcause mortality when included as a dichotomous variable (threshold of $<0.7$ ) or as a continuous variable in the multivariable model that included $\mathrm{FEV}_{1} \%$ predicted. $\mathrm{FEV}_{1} / \mathrm{FVC} \%$ was a significant independent predictor of death caused by pulmonary diseases.

Cox proportional-hazards regression was also performed with the independent variables as continuous variables excluded by backward stepwise elimination. Only predictors with $\mathrm{p}<0.05$ were kept in the final model. With all the variables in the model, the $\mathrm{HR}$ per $\% \mathrm{SpO}_{2}$ was $0.96(95 \%$ CI $0.92-1.00 ; \mathrm{p}=0.026)$ and the $\mathrm{HR}$ per $\% \mathrm{FEV}_{1} \%$ predicted was 0.99 (95\% CI 0.98-0.99; $\mathrm{p}<0.001$ ).

\section{Discussion}

In this study, we found that low oxygen saturation, defined as $\mathrm{SpO}_{2} \leq 95 \%$ measured by a single-point measurement with pulse oximetry, was associated with increased allcause mortality and mortality caused by pulmonary diseases. This has not been described previously in population studies. This association remained significant after adjusting for sex, age, history of smoking, self-reported diseases and respiratory symptoms, BMI, and CRP concentration. When including $\mathrm{FEV}_{1} \%$ predicted as a covariate, the $\mathrm{HR}$ for low $\mathrm{SpO}_{2}$ remained significant for pulmonary diseases but was no longer significant for all-cause mortality. The 


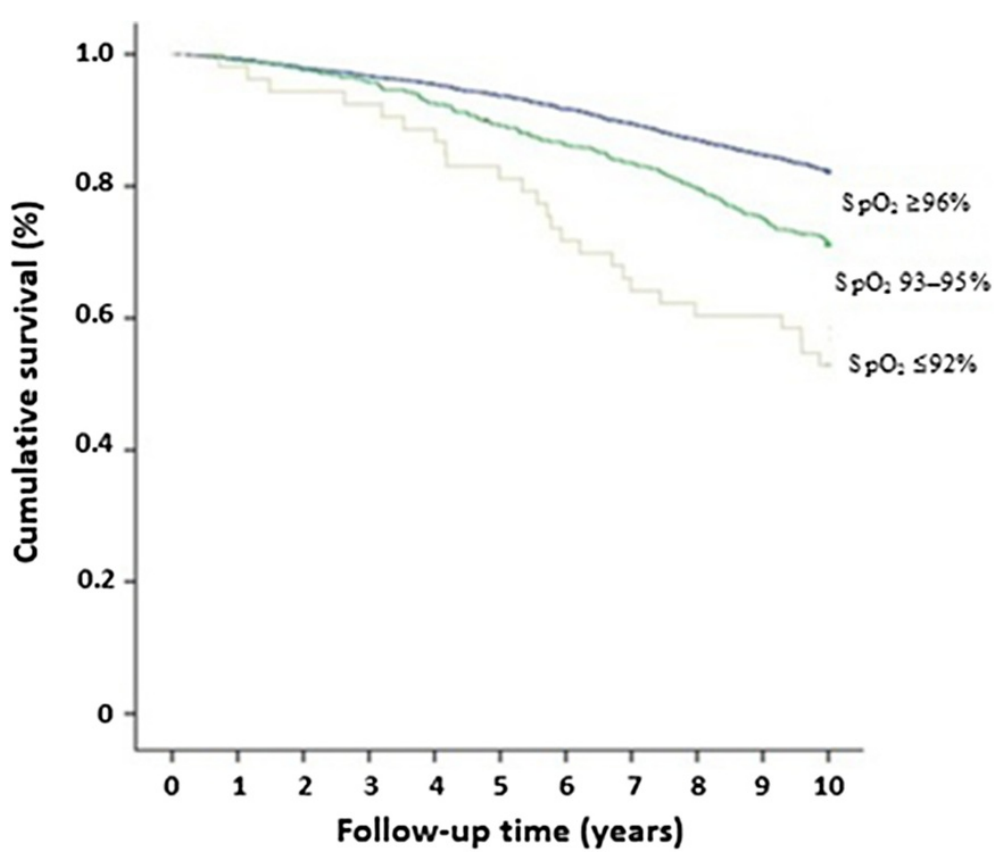

Figure 3 Kaplan-Meier survival curves for different levels of oxygen saturation $\left(\mathrm{SpO}_{2}\right)$.

severity of COPD and pulmonary diseases, and death by respiratory failure seem to be predicted by low $\mathrm{SpO}_{2}$ in addition to spirometry in the general population.

There are probably several explanations as to why oxygen saturation is associated with mortality. Low $\mathrm{SpO}_{2}$ is a marker of cardiopulmonary diseases, which are among the leading causes of death in this population. Thirtythree per cent of deaths were caused by CVD, and 14\% of deaths were caused by lung cancer and COPD. CVD predisposes a person to heart failure, which may affect pulmonary function and cause low $\mathrm{SpO}_{2}$. Even though $\mathrm{SpO}_{2}$ was not a significant predictor of death caused by CVD, we found a significant association with death caused by heart failure even when spirometry was included in the multivariable analysis. It is not surprising that low lung function, as measured by $\mathrm{SpO}_{2}$ and spirometry, is associated with death caused by pulmonary diseases. Lung cancer is associated with other respiratory diseases [32]. Severe respiratory disease in people with lung cancer limits the treatment modalities, among other surgery, and hence lower survival [33]. $\mathrm{SpO}_{2}$ has been shown to be a predictor of survival in lung cancer [34]. Spirometry has limitations in assessing the severity of pulmonary diseases, especially in the presence of reduced diffusion capacity as occurs in emphysema and interstitial lung disease. Therefore, $\mathrm{SpO}_{2}$ may be an independent risk factor when the results of other lung function tests, such as the 6 min walk test or diffusing capacity/ transfer factor of the lung for carbon monoxide, are not available.

\section{Comparison with previous studies}

In a recently published study [18], we reported a prevalence of $6.3 \%$ for $\mathrm{SpO}_{2} \leq 95 \%$ in Tromsø 6, which was lower than the $11.5 \%$ found in this study from Troms $\varnothing$ 5. The main reason for this difference is probably that a higher percentage was smokers in Tromsø 5 than in Tromsø 6 (25.9\% and 18.0\%, respectively). There was also a higher mean age in Tromsø 5: 65.8 years (SD 9.5) compared with 63.6 (SD 9.2) in Troms $\varnothing$ 6. The most important predictors of low $\mathrm{SpO}_{2}$ in Troms $\varnothing$ 6, BMI and $\mathrm{FEV}_{1} \%$ predicted, were significantly associated with mortality in a multivariable model in the present study. However, survival was not significantly lower for people with a higher BMI even though a higher BMI level was associated with low $\mathrm{SpO}_{2}$. Obesity is associated with sleep apnoea [35], obesity hypoventilation [36], diabetes, hypertension, and CVD [37]. Sleep apnoea is associated with lower daytime $\mathrm{PaO}_{2}$ even in people with normal spirometry values [38]. After correcting for these factors, obesity itself is not associated with higher mortality. In fact, for all-cause mortality it seems to have a protective effect. Although overweight and obesity may lead to decreased oxygen saturation, the risk of premature death seems not to be increased as long as the lung function is normal and other comorbidities are adjusted for. When including other comorbidities such as CVD, hypertension, and diabetes, other studies have found that obesity, when not very severe, does not increase mortality [39-41]. 
Table 3 Hazard ratios for 10 -year all-cause mortality in 3 different models*

\begin{tabular}{|c|c|c|c|c|c|c|c|c|c|}
\hline & \multicolumn{3}{|c|}{ Model 1} & \multicolumn{3}{|c|}{ Model 2} & \multicolumn{3}{|c|}{ Model 3} \\
\hline & $\mathrm{HR}$ & $(95 \% \mathrm{Cl})$ & $\mathrm{p}$-value & $\mathrm{HR}$ & $(95 \% \mathrm{Cl})$ & p-value & HR & $(95 \% \mathrm{Cl})$ & $\mathrm{p}$-value \\
\hline Age (years) & & & & 1.13 & $(1.12-1.14)$ & $<0.001$ & 1.12 & $(1.11-1.14)$ & $<0.001$ \\
\hline \multicolumn{10}{|l|}{ Sex } \\
\hline Female & & & & 1 & (reference) & & 1 & (reference) & \\
\hline Male & & & & 1.70 & $(1.49-1.95)$ & $<0.001$ & 1.66 & $(1.44-1.91)$ & $<0.001$ \\
\hline \multicolumn{10}{|c|}{ Self-reported diseases } \\
\hline CVD & 1.34 & $(1.17-1.54)$ & $<0.001$ & 1.18 & $(1.01-1.37)$ & 0.033 & 1.18 & $(1.01-1.37)$ & 0.035 \\
\hline Asthma & 1.33 & $(1.10-1.59)$ & 0.003 & 1.03 & $(0.84-1.25)$ & 0.81 & 0.92 & $(0.74-1.13)$ & 0.41 \\
\hline COPD & 1.75 & $(1.42-2.16)$ & $<0.001$ & 1.29 & $(1.02-1.64)$ & 0.036 & 1.13 & $(0.88-1.44)$ & 0.35 \\
\hline Diabetes & 2.08 & $(1.67-2.59)$ & $<0.001$ & 2.09 & $(1.66-2.63)$ & $<0.001$ & 1.88 & $(1.48-2.40)$ & $<0.001$ \\
\hline Hypertension & 1.20 & $(1.05-1.36)$ & 0.006 & 1.24 & $(1.08-1.43)$ & 0.003 & 1.24 & $(1.07-1.43)$ & 0.004 \\
\hline \multicolumn{10}{|l|}{ Smoking history } \\
\hline Never & 1 & (reference) & & 1 & (reference) & & 1 & (reference) & \\
\hline Former & 1.29 & $(1.10-1.52)$ & 0.002 & 1.24 & $(1.05-1.46)$ & 0.010 & 1.16 & $(0.98-1.38)$ & 0.082 \\
\hline Current & 2.11 & $(1.78-2.49)$ & $<0.001$ & 1.89 & $(1.58-2.26)$ & $<0.001$ & 1.68 & $(1.39-2.03)$ & $<0.001$ \\
\hline \multicolumn{10}{|c|}{ Self-reported symptoms } \\
\hline \multicolumn{10}{|c|}{ Dyspnoea $^{€}$} \\
\hline 0 & 1 & (reference) & & 1 & (reference) & & 1 & (reference) & \\
\hline 1 & 1.19 & $(1.05-1.36)$ & 0.007 & 1.06 & $(0.92-1.22)$ & 0.42 & 1.02 & $(0.89-1.18)$ & 0.76 \\
\hline$\geq 2$ & 1.71 & $(1.40-2.08)$ & $<0.001$ & 1.32 & $(1.06-1.64)$ & 0.015 & 1.15 & $(0.92-1.46)$ & 0.23 \\
\hline \multicolumn{10}{|c|}{ Chronic cough with sputum } \\
\hline Yes & 1.71 & $(1.42-2.07)$ & $<0.001$ & 1.28 & $(1.04-1.57)$ & 0.018 & 1.25 & $(1.01-1.54)$ & 0.042 \\
\hline \multicolumn{10}{|l|}{ BMI $\left(\mathrm{kg} / \mathrm{m}^{2}\right)$} \\
\hline$<18.5$ & 2.08 & $(1.35-3.20)$ & 0.001 & 1.99 & $(1.27-3.11)$ & 0.003 & 1.76 & $(1.08-2.84)$ & 0.022 \\
\hline $18.5-24.9$ & 1 & (reference) & & 1 & (reference) & & 1 & (reference) & \\
\hline $25.0-29.9$ & 0.85 & $(0.74-0.97)$ & 0.018 & 0.82 & $(0.71-0.95)$ & 0.008 & 0.84 & $(0.73-0.98)$ & 0.024 \\
\hline$\geq 30.0$ & 0.80 & $(0.68-0.96)$ & 0.015 & 0.68 & $(0.56-0.82)$ & $<0.001$ & 0.71 & $(0.58-0.87)$ & 0.001 \\
\hline \multicolumn{10}{|l|}{ CRP (mg/L) } \\
\hline$<5$ & 1 & (reference) & & 1 & (reference) & & 1 & (reference) & \\
\hline$\geq 5$ & 1.57 & $(1.35-1.82)$ & $<0.001$ & 1.39 & $(1.19-1.63)$ & $<0.001$ & 1.36 & $(1.16-1.60)$ & $<0.001$ \\
\hline \multicolumn{10}{|l|}{$\mathrm{FEV}_{1} \%$ predicted } \\
\hline$<50$ & 3.07 & $(2.46-3.81)$ & $<0.001$ & & & & 1.99 & $(1.51-2.61)$ & $<0.001$ \\
\hline $50-80$ & 1.54 & $(1.35-1.76)$ & $<0.001$ & & & & 1.29 & $(1.11-1.49)$ & 0.001 \\
\hline$\geq 80$ & 1 & (reference) & & & & & 1 & (reference) & \\
\hline \multicolumn{10}{|l|}{$\mathrm{FEV}_{1} / \mathrm{FVC} \%$} \\
\hline$<0.7$ & 1.69 & $(1.49-1.93)$ & $<0.001$ & & & & 1.11 & $(0.95-1.31)$ & 0.20 \\
\hline$\geq 0.7$ & 1 & (reference) & & & & & 1 & (reference) & \\
\hline \multicolumn{10}{|l|}{$\mathrm{SpO}_{2}(\%)$} \\
\hline$\leq 92$ & 1.99 & $(1.33-2.96)$ & 0.001 & 1.73 & $(1.15-2.60)$ & 0.008 & 1.42 & $(0.92-2.18)$ & 0.11 \\
\hline $93-95$ & 1.36 & $(1.15-1.60)$ & $<0.001$ & 1.27 & $(1.06-1.51)$ & 0.009 & 1.13 & $(0.94-1.36)$ & 0.19 \\
\hline$\geq 96$ & 1 & (reference) & & 1 & (reference) & & 1 & (reference) & \\
\hline
\end{tabular}

*Adjusted for age and sex in Model 1 and for all listed variables in the other two models.

$\epsilon$ Dyspnoea: 0, no dyspnoea, 1, dyspnoea while walking rapidly on level ground or up a moderate slope, $\geq 2$, dyspnoea while walking slowly on level ground, washing or dressing, or at rest.

Definition of abbreviations: HR, hazard ratio; $\mathrm{Cl}$, confidence interval; CVD, cardiovascular disease; COPD, chronic obstructive pulmonary disease; BMI, body mass index; CRP, C-reactive protein; $\mathrm{FEV}_{1}$, forced expiratory volume in $1 \mathrm{~s}$; FVC, forced vital capacity; $\mathrm{SpO}_{2}$, arterial oxygen saturation as measured by pulse oximetry. 
Table 4 Hazard ratios for 10 -year mortality due to pulmonary diseases ${ }^{*}$ in $\mathbf{3}$ different models $\boldsymbol{\epsilon}^{\epsilon}$

\begin{tabular}{|c|c|c|c|c|c|c|c|c|c|}
\hline & \multicolumn{3}{|c|}{ Model 1} & \multicolumn{3}{|c|}{ Model 2} & \multicolumn{3}{|c|}{ Model 3} \\
\hline & $\overline{\mathrm{HR}}$ & $(95 \% \mathrm{Cl})$ & $\overline{p \text {-value }}$ & $\overline{H R}$ & $(95 \% \mathrm{Cl})$ & $\overline{p \text {-value }}$ & HR & $(95 \% \mathrm{Cl})$ & p-value \\
\hline Age (years) & & & & 1.10 & $(1.07-1.12)$ & $<0.001$ & 1.08 & $(1.05-1.11)$ & $<0.001$ \\
\hline \multicolumn{10}{|l|}{ Sex } \\
\hline Female & & & & 1 & (reference) & & 1 & (reference) & \\
\hline Male & & & & 2.12 & $(1.50-2.98)$ & $<0.001$ & 1.95 & $(1.37-2.79)$ & $<0.001$ \\
\hline \multicolumn{10}{|c|}{ Self-reported diseases } \\
\hline CVD & 1.16 & $(0.81-1.67)$ & 0.42 & 1.21 & $(0.81-1.80)$ & 0.36 & 1.28 & $(0.85-1.93)$ & 0.23 \\
\hline Asthma & 3.64 & $(2.57-5.16)$ & $<0.001$ & 1.96 & $(1.32-2.92)$ & 0.001 & 1.53 & $(1.02-2.31)$ & 0.042 \\
\hline COPD & 5.18 & $(3.57-7.52)$ & $<0.001$ & 1.72 & $(1.10-2.69)$ & 0.017 & 1.31 & $(0.83-2.06)$ & 0.26 \\
\hline Diabetes & 1.73 & $(0.94-3.19)$ & 0.081 & 1.91 & $(1.01-3.64)$ & 0.048 & 1.50 & $(0.76-2.98)$ & 0.24 \\
\hline Hypertension & 0.65 & $(0.44-0.95)$ & 0.027 & 0.75 & $(0.49-1.14)$ & 0.18 & 0.74 & $(0.48-1.12)$ & 0.15 \\
\hline \multicolumn{10}{|l|}{ Smoking history } \\
\hline Never & 1 & (reference) & & 1 & (reference) & & 1 & (reference) & \\
\hline Former & 4.74 & $(2.41-9.34)$ & $<0.001$ & 3.78 & $(1.91-7.48)$ & $<0.001$ & 3.08 & $(1.55-6.12)$ & 0.001 \\
\hline Current & 14.21 & $(7.32-27.59)$ & $<0.001$ & 9.26 & $(4.69-18.28)$ & $<0.001$ & 6.35 & $(3.17-12.71)$ & $<0.001$ \\
\hline
\end{tabular}

Self-reported symptoms

Dyspnoea\#

0
1
$\geq 2$

$\begin{array}{ll}1 & \text { (reference) } \\ 1.64 & (1.17-2.31) \\ 3.39 & (2.16-5.33)\end{array}$

$\begin{array}{ll}1 & 1 \\ 0.005 & 1.09 \\ <0.001 & 1.31\end{array}$

(reference)

(0.75-1.58)

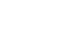

$$
1
$$

(reference)

Chronic cough with sputum

$$
\text { (2.16-5.33) }
$$

$(0.77-2.24)$

0.31

0.99

(0.67-1.45)

0.94

$$
\text { Yes }
$$

$1.85 \quad(1.24-2.77)$

0.003

1.86

$(1.25-2.79)$

0.002

1.12

$(0.64-1.94)$

0.70

BMI $\left(\mathrm{kg} / \mathrm{m}^{2}\right)$

$<18.5$
$18.5-24.9$
$25.0-29.9$
$\geq 30.0$

2.92

(1.17-7.30)

$$
0.022
$$

$$
1.75
$$

(reference)

$$
0.62
$$

(0.44-0.88)

$$
0.007
$$$$
1
$$

(0.63-4.88)

(reference)

$$
1.63
$$

$(1.07-2.48)$

0.022

CRP (mg/L)

$<5$

(0.42-1.03)

0.064

0.67

(0.47-0.96)

0.031

$$
\begin{aligned}
& 0.83 \\
& 1
\end{aligned}
$$

(0.20-3.46)

0.80

0.67

(0.41-1.08)

0.099

0.73

(reference)

(reference)

(1.32-2.74)

0.001

(reference)

(0.77-1.68)

0.53

$<0.001$

$<50$

16.35

(10.51-25.43)

\begin{tabular}{|c|c|c|c|c|c|c|c|c|c|}
\hline$\leq 92$ & 9.12 & $(4.99-16.67)$ & $<0.001$ & 5.19 & (2.70-9.99) & $<0.001$ & 3.17 & $(1.53-6.56)$ & 0.002 \\
\hline $93-95$ & 3.32 & $(2.33-4.71)$ & $<0.001$ & 2.54 & $(1.75-3.68)$ & $<0.001$ & 1.97 & $(1.33-2.92)$ & 0.001 \\
\hline$\geq 96$ & 1 & (reference) & & 1 & (reference) & & 1 & (reference) & \\
\hline
\end{tabular}

50-80

$\geq 80$

3.11

(2.10-4.60)

$<0.001$

$\mathrm{FEV}_{1} /$ FVC\%

$\begin{array}{llll}<0.7 & 5.18 & (3.70-7.25) & <0.001 \\ \geq 0.7 & 1 & \text { (reference) } & \end{array}$

$\mathrm{SpO}_{2}(\%)$

"Pulmonary diseases: including COPD, asthma, interstitial lung disease, sequelae of tuberculosis, lung cancer.

${ }^{\epsilon}$ Adjusted for age and sex in Model 1 and for all listed variables in the other two models.

\#Dyspnoea: 0, no dyspnoea; 1, dyspnoea while walking rapidly on level ground or up a moderate slope, $\geq 2$, dyspnoea walking slowly on level ground, washing or dressing, or at rest.

Definition of abbreviations: HR, hazard ratio; $\mathrm{Cl}$, confidence interval; CVD, cardiovascular disease; COPD, chronic obstructive pulmonary disease; BMI, body mass index; CRP, C-reactive protein; $\mathrm{FEV}_{1}$, forced expiratory volume in $1 \mathrm{~s}$; FVC, forced vital capacity; $\mathrm{SpO}_{2}$, arterial oxygen saturation as measured by pulse oximetry. 
$\mathrm{FEV}_{1} / \mathrm{FVC} \%$ was not observed to be significantly associated with all-cause mortality in the multivariable analysis. Both restrictive and obstructive airway diseases have been associated with increased mortality in previous studies $[19,42]$, and both moderate to very severe COPD and restrictive lung diseases involve reduced $\mathrm{FEV}_{1} \%$ predicted. For the participants with an $\mathrm{FEV}_{1} \%$ predicted of $<50 \%$, almost $90 \%$ had an $\mathrm{FEV}_{1} / \mathrm{FVC} \%<70$, suggesting that the low oxygen saturation observed in this group was probably caused by COPD.

Male sex is associated with a shorter life expectancy than female sex. More men are former smokers and they tend to smoke more pack-years than women, which may explain some of the differences in life expectancy. The prevalence of CVD is higher in men. Similar findings have been found in another study [42].

Contrary to our previous study, we did in the current study not find that increased haemoglobin concentration was significantly associated with low $\mathrm{SpO}_{2}$. Few participants had a high haemoglobin concentration, and this value was missing in $11 \%$ of the participants. This might explain the lack of association in this study.

In a recent study, Smith et al. [43] reported increased mortality rates in hospitalized patients with an $\mathrm{SpO}_{2}<$ $96 \%$. Increased mortality has also been found in emergency care patients with a low $\mathrm{SpO}_{2}[8,9] . \mathrm{SpO}_{2}$ may be a good predictor of mortality in situations where spirometry is not available and in populations with a higher frequency of low $\mathrm{SpO}_{2}$, especially when used as part of a risk-scoring system.

\section{Strengths and weaknesses}

This study was based on a single-point measurement of $\mathrm{SpO}_{2}$. We have not checked the reproducibility, but we know that the group with the lowest $\mathrm{SpO}_{2}(\leq 92 \%)$ in the follow-up examinations also showed consistently low values for $\mathrm{SaO}_{2}$ in blood gas analysis. Oxygen saturation can vary during the day, especially during activity and at night in people with a pulmonary disease such as COPD [44]. Baseline $\mathrm{SpO}_{2}$ (at rest) has been shown to predict oxygen desaturation during activity [3] and at night [4]. $\mathrm{SpO}_{2}$ can also be in the normal range even though $\mathrm{FEV}_{1} \%$ predicted is $<50 \%$.

The measurement of $\mathrm{SpO}_{2}$ could be a limitation because the accuracy of the device is \pm 2 digits. We tried to compensate for this possible confounding factor by using the highest of three measurements and categorizing the participants into groups.

The group with $\mathrm{SpO}_{2} \leq 92 \%$ in this population was small and comprised only $1.0 \%$ of the entire population. One reason may be that people with the lowest values were too sick to participate. We might have found a stronger association with $\mathrm{SpO}_{2}$ in groups of patients with diseases such as COPD because such groups have a higher frequency of low $\mathrm{SpO}_{2}$.
The participation rate was lower in the oldest age group and in the youngest men. This might have affected our results by missing the sickest (oldest) and healthiest (youngest) groups.

We did not measure post-bronchodilator spirometry. A previous study has shown that this is probably not necessary when mortality is evaluated in population studies [42].

Recall bias and misclassification errors are major concerns when using questionnaires. A stronger association between smoking and mortality may have been observed if more valid data on pack-years had been obtained.

Measuring oxygen saturation by pulse oximetry has important limitations [45], especially when measuring values at the lower levels. Saturation may be overestimated in heavy smokers because high carboxyhaemoglobin levels may cause overestimation of the true $\mathrm{SpO}_{2}$. To validate the data for a particular device, future studies could include gas analysis in a subsample for comparison.

The cause of death may be uncertain or wrong in many instances because only a small percentage has an autopsy done (10-12\% in Norway). Among the participants who died during this study, $36.9 \%$ had an $\mathrm{FEV}_{1} / \mathrm{FVC} \%<70$, and $9.2 \%$ reported having COPD. COPD as the main diagnosis or as one of the comorbidities was reported by only $6.5 \%$.

\section{Conclusions}

We observed that lower values from pulse oximetry were associated with increased all-cause mortality in the general adult population. This was probably because of the strong association with death caused by pulmonary diseases. The association was weakened and no longer statistically significant after adjusting for $\mathrm{FEV}_{1} \%$ predicted but remained significant for death caused by pulmonary diseases. Pulse oximetry is easy and safe to perform, and may be particularly useful in risk assessment when spirometry is not an option and when added to spirometry for assessing the risk of death because of pulmonary disease. Low pulse oximetry values found in a patient should warrant further examination.

\section{Competing interests}

The authors declare that they have no competing interests.

\section{Authors' contributions}

Concept and design (MLV, HM, UA). Data collection (HM). Data analysis and interpretation (MLV, TW, HM). Drafting the manuscript (MLV, HM). Revision and final approval of the manuscript (all authors).

\section{Acknowledgements}

MLV was funded by Northern Norway Regional Health Authority.

\section{Author details}

'Department of Respiratory Medicine, University Hospital of North Norway, 9038 Troms $\varnothing$, Norway. ${ }^{2}$ Department of Community Medicine, University of Troms $\varnothing$, Troms $\varnothing$, Norway. ${ }^{3}$ Department of Clinical Medicine, University of Tromsø, Tromsø, Norway. 
Received: 26 August 2014 Accepted: 20 January 2015 Published online: 12 February 2015

\section{References}

1. Crapo RO, Jensen RL, Hegewald MATH, Tashkin DP. Arterial blood gas reference values for sea level and an altitude of 1,400 meters. Am J Respir Crit Care Med. 1999:160:1525-31.

2. Klaestrup E, Trydal T, Pedersen JF, Larsen JM, Lundbye-Christensen S, Kristensen SR. Reference intervals and age and gender dependency for arterial blood gases and electrolytes in adults. Clin Chem Lab Med 2011:49:1495-500.

3. Little SA, Elkholy MM, Chalmers GW, Farouk A, Patel KR, Thomson NC. Predictors of nocturnal oxygen desaturation in patients with COPD. Respir Med. 1999;93:202-7.

4. Knower MT, Dunagan DP, Adair NE, Chin Jr R. Baseline oxygen saturation predicts exercise desaturation below prescription threshold in patients with chronic obstructive pulmonary disease. Arch Intern Med. 2001;161:732-6.

5. Edvardsen A, Akerø A, Christensen CC, Ryg M, Skjonsberg OH. Air travel and chronic obstructive pulmonary disease: a new algorithm for pre-flight evaluation. Thorax. 2012;67:964-9.

6. Canet J, Gallart L, Gomar C, Paluzie G, Valles J, Castillo J, et al. Prediction of postoperative pulmonary complications in a population-based surgical cohort. Anesthesiology. 2010;113:1338-50.

7. Roberts CM, Bugler JR, Melchor R, Hetzel MR, Spiro SG. Value of pulse oximetry in screening for long-term oxygen therapy requirement. Eur Respir J. 1993;6:559-62

8. Buist M, Bernard S, Nguyen TV, Moore G, Anderson J. Association between clinically abnormal observations and subsequent in-hospital mortality: a prospective study. Resuscitation. 2004;62:137-41.

9. Herlitz J, Hansson E, Ringvall E, Starke M, Karlson BW, Waagstein L. Predicting a life-threatening disease and death among ambulancetransported patients with chest pain or other symptoms raising suspicion of an acute coronary syndrome. Am J Emerg Med. 2002;20:588-94.

10. Kellett J, Deane B, Gleeson M. Derivation and validation of a score based on hypotension, oxygen saturation, low temperature, ECG changes and loss of independence (HOTEL) that predicts early mortality between $15 \mathrm{~min}$ and $24 \mathrm{~h}$ after admission to an acute medical unit. Resuscitation. 2008;78:52-8.

11. Olsson T, Terent A, Lind L. Rapid Emergency Medicine Score can predict long-term mortality in nonsurgical emergency department patients. Acad Emerg Med. 2004;11:1008-13.

12. Olsson T, Terent A, Lind L. Rapid Emergency Medicine score: a new prognostic tool for in-hospital mortality in nonsurgical emergency department patients. J Intern Med. 2004;255:579-87.

13. Van Spall HG, Atzema C, Schull MJ, Newton GE, Mak S, Chong A, et al. Prediction of emergent heart failure death by semi-quantitative triage risk stratification. PLoS One. 2011;6:e23065.

14. Duckitt RW, Buxton-Thomas R, Walker J, Cheek E, Bewick V, Venn R, et al. Worthing physiological scoring system: derivation and validation of a physiological early-warning system for medical admissions. An observational, population-based single-centre study. Br J Anaesth. 2007:98:769-74

15. Celli BR, Cote CG, Lareau SC, Meek PM. Predictors of Survival in COPD: more than just the FEV1. Respir Med. 2008;102 Suppl 1:S27-35.

16. Ramirez-Venegas A, Sansores RH, Perez-Padilla R, Regalado J, Velazquez A, Sanchez C, et al. Survival of patients with chronic obstructive pulmonary disease due to biomass smoke and tobacco. Am J Respir Crit Care Med. 2006;173:393-7.

17. Trauer JM, Gielen CA, Aminazad A, Steinfort CL. Ambulatory oximetry fails to predict survival in COPD with mild-to-moderate hypoxaemia. Respirology. 2013;18:377-82.

18. Vold ML, Aasebø U, Hjalmarsen A, Melbye H. Predictors of oxygen saturation $\leq 95 \%$ in a cross-sectional population based survey. Respir Med. 2012;106:1551-8.

19. Mannino DM, Buist AS, Petty TL, Enright PL, Redd SC. Lung function and mortality in the United States: data from the first National Health and Nutrition Examination Survey follow up study. Thorax. 2003;58:388-93.

20. Flegal KM, Graubard BI, Williamson DF, Gail MH. Cause-specific excess deaths associated with underweight, overweight, and obesity. JAMA. 2007;298:2028-37.
21. Hotchkiss JW, Leyland AH. The relationship between body size and mortality in the linked Scottish Health Surveys: cross-sectional surveys with follow-up. Int J Obes (Lond). 2011;35:838-51.

22. Gudmundsson G, Ulrik CS, Gislason T, Lindberg E, Brondum E, Bakke $P$, et al. Long-term survival in patients hospitalized for chronic obstructive pulmonary disease: a prospective observational study in the Nordic countries. Int J Chron Obstruct Pulmon Dis. 2012;7:571-6.

23. Landbo C, Prescott E, Lange P, Vestbo J, Almdal TP. Prognostic value of nutritional status in chronic obstructive pulmonary disease. Am J Respir Crit Care Med. 1999;160:1856-61.

24. Mahmood SS, Levy D, Vasan RS, Wang TJ. The Framingham Heart Study and the epidemiology of cardiovascular disease: a historical perspective. Lancet. 2014:383:999-1008.

25. Zacho J, Tybjærg-Hansen A, Nordestgaard BG. C-reactive protein and all-cause mortality - the Copenhagen City Heart Study. Eur Heart J. 2010;31:1624-32.

26. Dahl M, Vestbo J, Lange P, Bojesen SE, Tybjaerg-Hansen A, Nordestgaard BG. C-reactive protein as a predictor of prognosis in chronic obstructive pulmonary disease. Am J Respir Crit Care Med. 2007;175:250-5.

27. Jacobsen BK, Eggen AE, Mathiesen EB, Wilsgaard T, Njølstad I. Cohort profile: the Tromsø Study. Int J Epidemiol. 2012;41:961-7.

28. Standardization of spirometry, 1994 update. American Thoracic Society. Am J Respir Crit Care Med. 1995;152:1107-36.

29. Langhammer A, Johnsen R, Gulsvik A, Holmen TL, Bjermer L. Forced spirometry reference values for Norwegian adults: the Bronchial Obstruction in Nord-Trøndelag Study. Eur Respir J. 2001;18:770-9.

30. Skjelbakken T, Dahl IM, Løchen ML. Changes in body mass index and smoking habits have a different impact on hemoglobin concentration in men and women: a longitudinal follow-up of the Tromso Study, 1994-2002. Gend Med. 2010;7:230-9.

31. Melbye H, Halvorsen DS, Hartz I, Medbø A, Brox J, Eggen AE, et al. Bronchial airflow limitation, smoking, body mass index, and statin use are strongly associated with the C-reactive protein level in the elderly. The Tromso Study 2001. Respir Med. 2007;101:2541-9.

32. Denholm R, Schuz J, Straif K, Stucker I, Jockel KH, Brenner DR, et al.. Is previous respiratory disease a risk factor for lung cancer? Am J Respir Crit Care Med 2014, in press.

33. Brunelli A, Charloux A, Bolliger CT, Rocco G, Sculier JP, Varela G, et al. ERS/ ESTS clinical guidelines on fitness for radical therapy in lung cancer patients (surgery and chemo-radiotherapy). Eur Respir J. 2009;34:17-41.

34. Martins SJ, Ho N, Cavamura SO, Harada CM, Yamamoto CA, Takagaki TY. Lung cancer symptoms and pulse oximetry in the prognostic assessment of patients with lung cancer. BMC Cancer. 2005;5:72.

35. Young $T$, Shahar E, Nieto FJ, Redline S, Newman AB, Gottlieb DJ, et al. Predictors of sleep-disordered breathing in community-dwelling adults: the Sleep Heart Health Study. Arch Intern Med. 2002;162:893-900

36. Chau EH, Lam D, Wong J, Mokhlesi B, Chung F. Obesity hypoventilation syndrome: a review of epidemiology, pathophysiology, and perioperative considerations. Anesthesiology. 2012;117:188-205.

37. Guh DP, Zhang W, Bansback N, Amarsi Z, Birmingham CL, Anis AH. The incidence of co-morbidities related to obesity and overweight: a systematic review and meta-analysis. BMC Public Health. 2009;9:88.

38. Verin E, Tardif C, Pasquis P. Prevalence of daytime hypercapnia or hypoxia in patients with OSAS and normal lung function. Respir Med. 2001;95:693-6.

39. Hotchkiss JW, Davies CA, Leyland AH. Adiposity has differing associations with incident coronary heart disease and mortality in the Scottish population: cross-sectional surveys with follow-up. Int J Obes (Lond). 2013:37:732-9.

40. Lavie CJ, McAuley PA, Church TS, Milani RV, Blair SN. Obesity and cardiovascular diseases: implications regarding fitness, fatness, and severity in the obesity paradox. J Am Coll Cardiol. 2014;63:1345-54.

41. Winter JE, Maclnnis RJ, Wattanapenpaiboon N, Nowson CA. BMI and all-cause mortality in older adults: a meta-analysis. Am J Clin Nutr. 2014:99:875-90

42. Mannino DM, Diaz-Guzman E, Buist S. Pre- and post-bronchodilator lung function as predictors of mortality in the Lung Health Study. Respir Res. 2011;12:136

43. Smith GB, Prytherch DR, Watson D, Forde V, Windsor A, Schmidt PE, et al. $\mathrm{S}_{\mathrm{p}} \mathrm{O}_{2}$ values in acute medical admissions breathing air-implications for the 
British Thoracic Society guideline for emergency oxygen use in adult patients? Resuscitation. 2012;83:1201-5.

44. Casanova C, Hernandez MC, Sanchez A, Garcia-Talavera I, de Torres JP, Abreu J, et al. Twenty-four-hour ambulatory oximetry monitoring in COPD patients with moderate hypoxemia. Respir Care. 2006;51:1416-23.

45. Jensen LA, Onyskiw JE, Prasad NG. Meta-analysis of arterial oxygen saturation monitoring by pulse oximetry in adults. Heart Lung. 1998;27:387-408.

Submit your next manuscript to BioMed Central and take full advantage of:

- Convenient online submission

- Thorough peer review

- No space constraints or color figure charges

- Immediate publication on acceptance

- Inclusion in PubMed, CAS, Scopus and Google Scholar

- Research which is freely available for redistribution 